\title{
THERMAL AND PHYSICAL CHANGES ACCOMPANY- ING THE HEATING OF HARDENED CARBON STEELS
}

\author{
By Howard Scott and H. Gretchen Movius
}

CONTENTS
I. Introduction $\ldots \ldots \ldots \ldots \ldots \ldots \ldots \ldots \ldots \ldots \ldots \ldots \ldots \ldots \ldots \ldots \ldots \ldots \ldots \ldots \ldots \ldots \ldots$

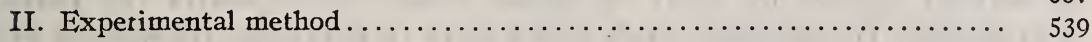

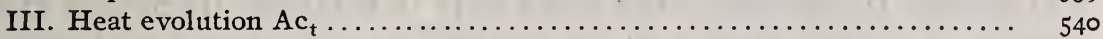

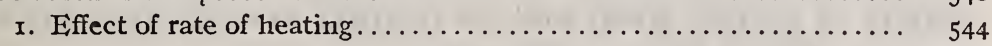

2. Effect of tempering temperature................... 545

3. Effect of time at tempering temperature............... 546

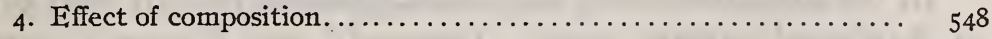

5. Effect of austenitic structure.................... 549

IV. Relation of changes in physical properties to heat evolution......... $55^{\text {I }}$

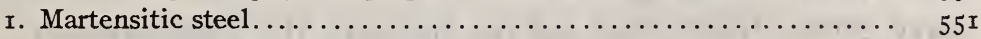

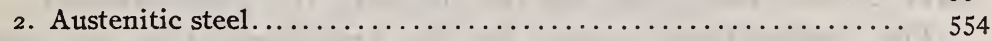

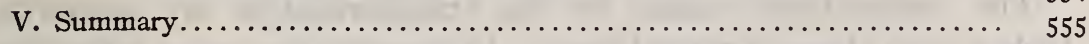

\section{INTRODUCTION}

The widespread interest which has been recently expressed in the properties of steel in the "blue-heat" range and in the subject of "temper brittleness" makes it highly desirable to study in detail the transformations in steel below the $A_{1}$ change. In a previous paper ${ }^{1}$ the authors have pointed out certain thermal characteristics of the magnetic change in cementite as observed in annealed steels by means of thermal analysis. In this paper the subject under investigation is the thermal change observed in hardened steels on heating below $\mathrm{Ac}_{1}$.

Outside of the possible bearing of such information on the lowtemperature properties mentioned, there remains the desirability of establishing fundamental characteristics of steel. The one in question is of particular value in that it may furnish a practical basis for defining the natural boundary between martensite and the troostite of tempering, which from present information is very indefinite.

A survey of the changes in some of the physical properties of carbon steels on tempering would, on account of certain inconsistencies, lead one to doubt the existence of a sharp demarcation between the constituents-martensite and troostite. Heating 
curves of hardened steels, however, have shown a well-marked heat evolution ending around $300^{\circ} \mathrm{C}$. Such heat evolution would be expected from the usual conception of the formation of martensite; namely, that one or more of the transformations occurring on slow cooling are suppressed by quenching. The consummation of the suppressed transformation (or transformations) is a manifestation of the completion of the constitutional change and, therefore, evidence of a boundary between two constituents, presumably martensite and troostite. Whether the end of this heat evolution should be used to define those constituents the future will decide; the present work seeks only to establish its nature in a variety of carbon steels and its relation to accompanying changes in some of the physical properties.

In the literature some work has appeared on this heat evolution in hardened carbon steels. Osmond ${ }^{2}$ and Maurer ${ }^{2}$ have given inverse-rate heating curves; Heyn and Bauer $^{3}$ and Portevin ${ }^{3}$ have given differential curves showing the phenomenon.

The temperature values for the transformation are somewhat higher than those obtained here. In general, the curve inflections are neither prominent enough nor the statement of operating details sufficient to allow of a precise definition of the transformation characteristics. Also the effect of important variables has not been determined. This phenomenon has been observed also by continuous measurement of the changes in some physical properties on heating. Grenet ${ }^{4}$ detected an inflection in the expansion and electric-resistance curves of a high-carbon steel, Chevenard $^{5}$ in expansion curves, and Honda ${ }^{6}$ in magneticinduction curves. The magnetic curves are the only ones which seem to follow closely the progress of the heat change. Brush? has made extensive observations on the heat evolution at ordinary temperatures in recently hardened steels. He noted a heat evolution, greatest immediately after hardening, gradually diminishing in rate with time and becoming imperceptible after several weeks. The physical changes accompanying this spontaneous evolution were very 'small in comparison with those accompanying even slight tempering.

While the present research is confined to carbon steels because of their fundamental importance, it is being extended to alloy

2 Osmond, J. Iron and Steel Inst., p. 38; No. I, I89o. Maurer, Rev. de Met., 5, p. $7 x$; 1908.

3 Heyn and Bauer, J. Iron and Steel Inst., 79, p. 109; 1909. Portevin, Rev. de Met., 13, p. 9; 1916.

1 Grenet, Rev. de Met., 1, p. 353; 1904.

- Chevenard, Rev. de Met., 14, p. 6ro; rgr7.

- Honda, Sci. Reports Tohoku Imp. Univ., 6, p. 149; x917.

7 Brush, Bull. A. I. M. M. E. No. 153, p. 2389; 1919. 
steels in order to obtain further light on the effect and function of the alloying elements.

\section{EXPERIMENTAL METHOD}

The inverse-rate method of obtaining thermal curves has been used at the Bureau of Standards as the most effective and satisfactory method for studying the transformations in steel. Used in connection with the apparatus already described ${ }^{8}$ excellent curves can be obtained at the low temperatures where the heat evolution under examination is found. The details of mounting, size of sample, and operation are given in the above reference. A temperature interval corresponding to 20 microvolts on a platinum, platinum-rhodium thermocouple was used in this investigation.

TABLE 1.-Results of Chemical Analyses of Steels Investigated

\begin{tabular}{|c|c|c|c|c|}
\hline C & $\mathbf{M n}$ & Si & $\mathbf{P}$ & $\mathbf{s}$ \\
\hline Per cent & Per cent & Per cent & Per cent & Per cent \\
\hline 0.40 & ............. & 0.01 & $\ldots .$. & $\cdots$ \\
\hline .44 & 1.00 & .02 & ......... & - $\ldots \ldots$ \\
\hline$a .46$ & .35 &, 06 & 0.02 & 0.05 \\
\hline a. 73 & .38 & .01 & .04 & .05 \\
\hline .95 & .22 & .24 & .02 & .01 \\
\hline 1.01 & .............. & .01 & ......... & .005 \\
\hline 1.94 & & .01 & 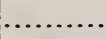 & .005 \\
\hline
\end{tabular}

a Furnished by courtesy of Carnegie Steel Co.

The materials studied were seven steels of the compositions given in Table I. Heating for quenching, as noted on the curves and in the tabulated results, was carried out on the prepared samples by introduction into an electrically heated alundum-tube furnace wound with resistance wire. Charcoal was present to reduce oxidation, and a platinum, platinum-rhodium thermocouple was used for the measurement of temperature. In tempering, the specimen was heated 30 minutes in an oil or nitrate bath, as required by the temperature. Temperatures below $300^{\circ} \mathrm{C}$ were measured with a mercury thermometer.

All samples of the quenched 0.95 per cent $C$ steel not receiving subsequent tempering were run within from I to 3 days after quenching. All the other steels not tempered were run within from 6 to 16 days after treatment, excepting the r.or per cent $\mathrm{C}$ and I.94 per cent $\mathrm{C}$ steels (curve $I$ ), which were run the day following treatment.

${ }^{8}$ Scott and Freeman, Bull. A. I. M. M. E. No. 152, p. 1429; 1919. Also B. S. Sci. Papers, No. 348. 


\section{HEAT EVOLUTION Act}

The principal phenomenon under consideration here, the heat evolution on heating hardened carbon steels, will be designated as "Ac $c_{t}$," a notation used by one of the authors ${ }^{3}$ for the same phenomenon in a high-alloy steel.

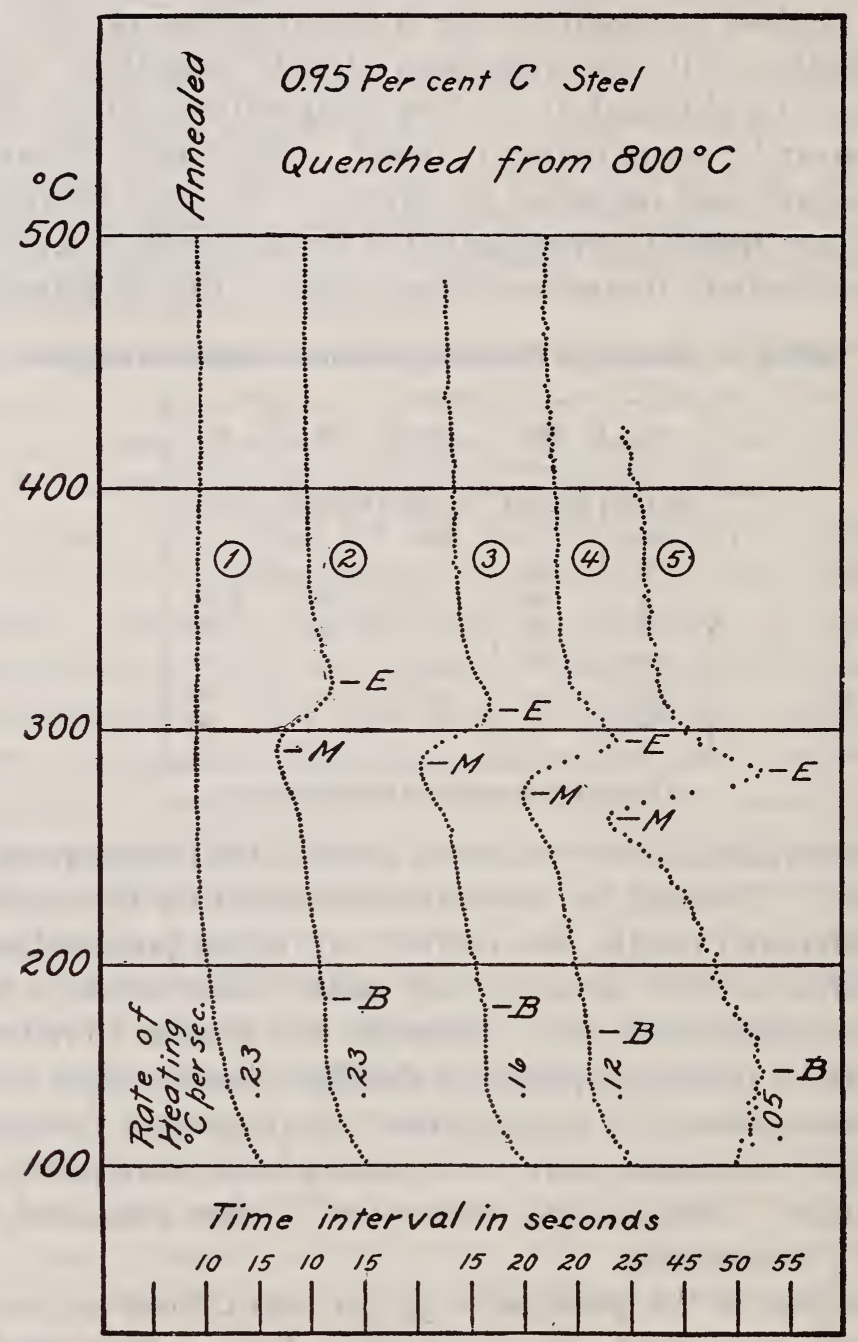

FIG. I.-Inverse-rate heating curves of hardened steel, showing effect of rate of heating on $A c_{t}$

The thermal curves, taken to show the effect of several variables on the transformation $\mathrm{Ac}_{\mathrm{t}}$, are shown in Figs. I, 2, 3, 4, and 5 . For the reduction of the thermal-curve data to tabular form, the

${ }^{\circ}$ Scott. Bull. A. I. M. M. E. No. 146, p. 157; Feb., 1919. Also B. S. Sci. Papers, No. 335. 


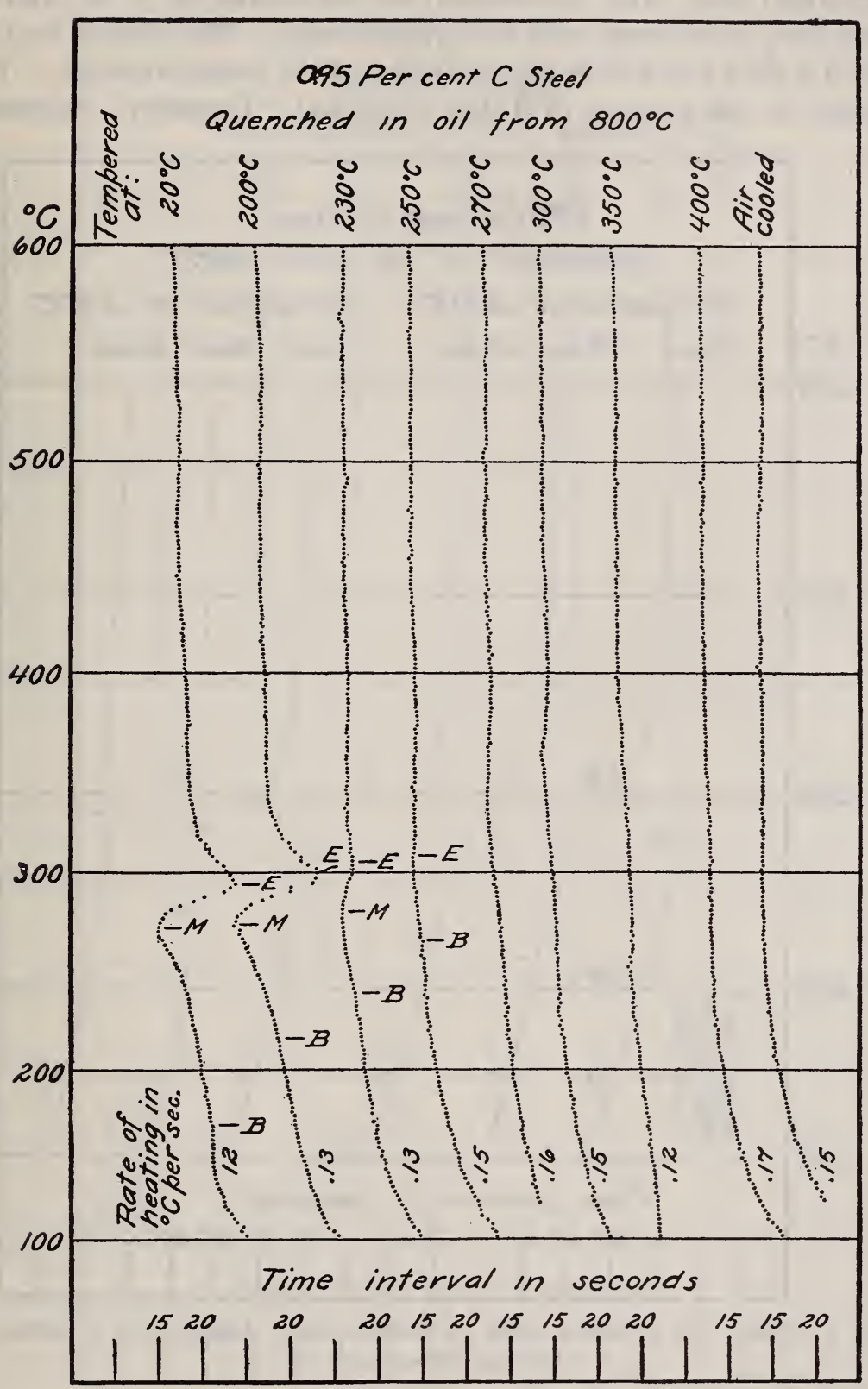

FIG. 2.-Inverse-rate heating curves of hardened steel, showing effect of previous tempering for 30 minutes on $A c_{t}$ 
temperatures of the principal curve bends caused by the $A c_{t}$ transformation were taken as denoted on the curves by $B, M$, and $E$, beginning, maximum, and end, respectively. The rate of heating given is that just before the beginning of the transformation. The values in the column of Table 2 marked "Intensity" represent

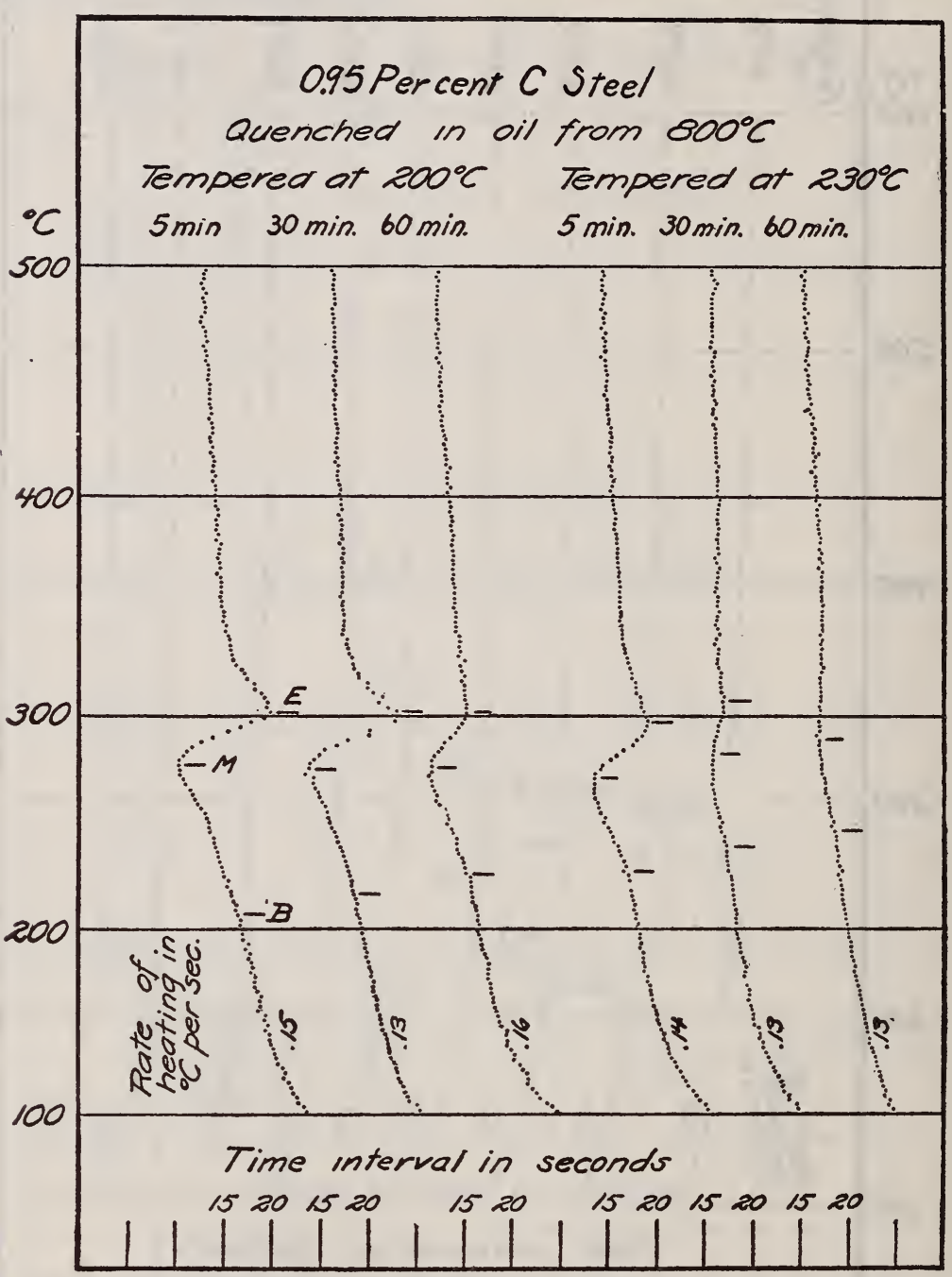

FIG. 3.-Inverse-rate of heating curves on hardened steels, showing effect of duration of previous tempering on $A c_{t}$

the difference in seconds between the time at the maximum and at the end of $A c_{t}$, except in the case of the austenitic steel, where they represent temperature drop.

The temperature of the maximum of $\mathrm{Ac}_{1}$ (maximum temperature before decalescence when that phenomenon was observed) is also 


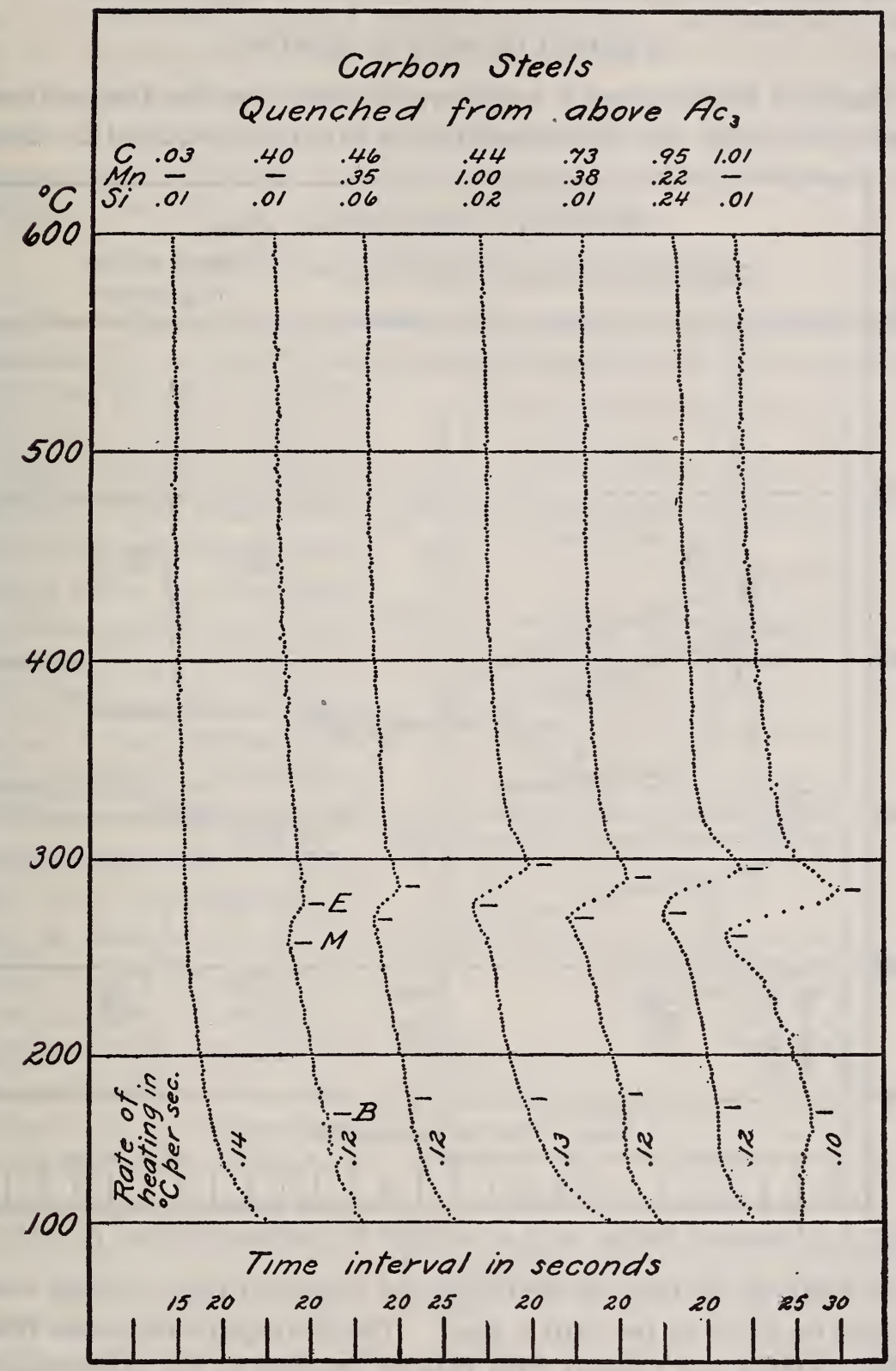

FIG. 4.-Inverse-rate heating curves of quenched steel, showing effect of composition $4218^{\circ}-20-2$ 
given, but the heating curves are not plotted to show $\mathrm{Ac}_{1}$, in order to avoid excessive reduction of the curves on reproduction.

\section{EFFECT OF RATE OF HEATING}

Rate of heating has a considerable effect on the temperature and form of $A c_{t}$ for the comparatively fast rates required by ther-

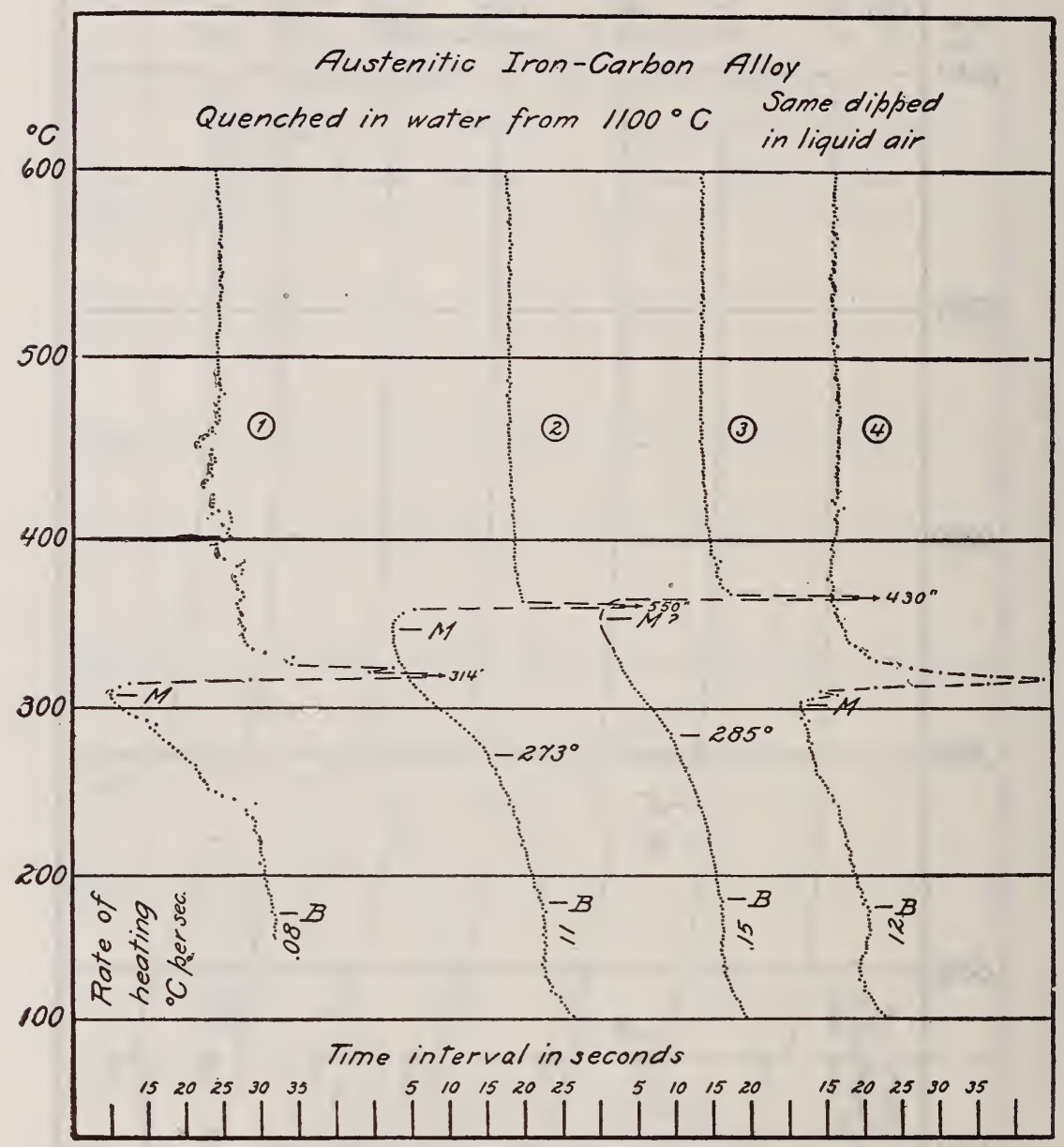

Fig. 5.-Inverse-rate heating curves of austenitic iron-carbon alloy (I.94 per cent C)

mal analysis, as may be seen from the curves of Fig. I, which were taken on the 0.95 per cent $\mathrm{C}$ steel. The principal data taken from these curves are plotted with rate of heating as the abscissas, in Fig. 6. It will be noted from this figure that the temperature characteristics of $A c_{t}$ for zero rate are 155,250 , and $260^{\circ} \mathrm{C}$, respectively, for the beginning, maximum, and end of the transformation. This appears to represent the progress of the transformation 
for a tempering time approximating normal tempering conditions, probably about 30 minutes. From the sharpness of the beginning of the transformation it would appear that the quenched steel is the equivalent of a steel instantaneously cooled and then drawn in the neighborhood of $150^{\circ} \mathrm{C}$. Fig. 6 illustrates this interesting point: That for the size of specimen used in this case there is no appreciable difference between the thermal characteristics of an oil-quenched and of a water-quenched specimen.

\section{EFFECT OF TEMPERING TEMPERATURE}

The heating curves represent the progress of tempering for a necessarily very short time at any temperature in the $\mathrm{Ac}_{t}$ range. To show the effect of holding for a definite time at several tempering temperatures on the characteristics of $A c_{t}$, heating curves were taken on specimens of the 0.95 per cent $\mathrm{C}$ steel quenched in oil from $800^{\circ}$ $\mathrm{C}$ and tempered 30 minutes at the temperatures given in Fig. 2 and Table 2.

From a consideration of these data it may be seen: (I) That the beginning of $A c_{t}$ is from Io to $I 7^{\circ} \mathrm{C}$ higher than the tempering temperature when that is above $200^{\circ} \mathrm{C}$; (2) that the transformation is completed at a temperature between $25^{\circ}$ and $270^{\circ} \mathrm{C}$; and (3) that for each temperature up to $250^{\circ} \mathrm{C}$ there is a definite and characteristic form of curve. The

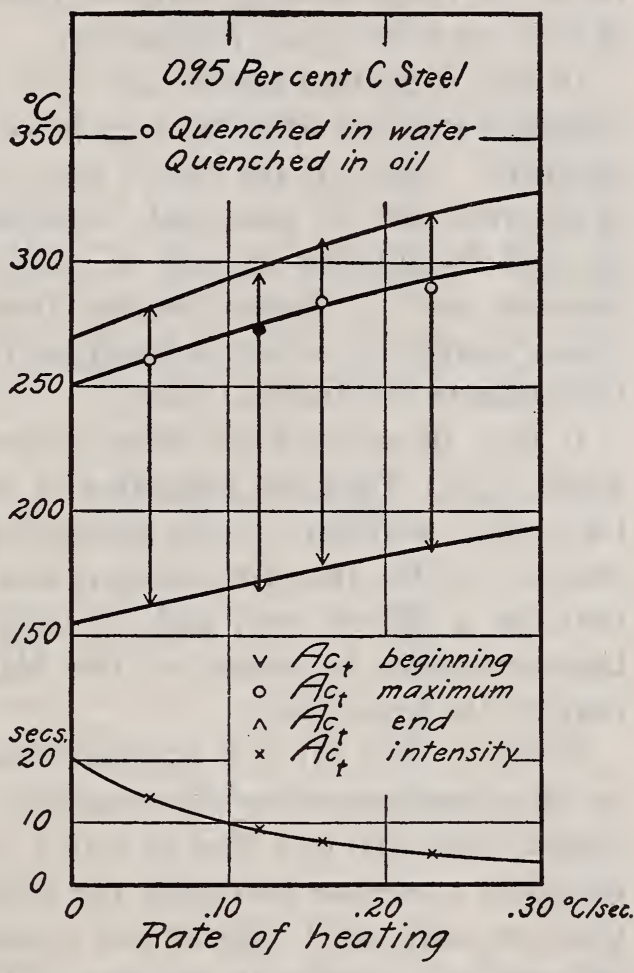

FIG. 6.-Effect of rate of heating on temperature and intensity of heat evolution of 0.95 per cent $C$ steel estimated temperature of the end of $A c_{t}$ for zero rate $\left(260^{\circ} \mathrm{C}\right)$ is, therefore, from (2) in practical agreement with the end of the transformatior for a tempering period of 30 minutes. From (I) and (3) it is evident that the heating curves might be used to estimate the previous tempering temperature within certain limits. 
It may be of interest to note that, for a tempering temperature of $270^{\circ}$ and $300^{\circ} \mathrm{C}$ (Fig. 2), there is a slight deflection of the curves to the right, indicating an absorption of heat over the range of about $35^{\circ}$ to $45^{\circ} \mathrm{C}$, which is in conformity with the observations of Heyn and Bauer ${ }^{10}$ under similar conditions.

\section{EFFECT OF TIME AT TEMPERING TEMPERATURE}

It has long been recognized that the time of holding at a tempering temperature has a very considerable effect on the resulting physical properties, and it is even held that a long time at a low temperature is equivalent to a short time at a higher temperature. The thermal curves of steels tempered for different lengths of time in the $\mathrm{Ac}_{\mathrm{t}}$ range should, therefore, throw some light on the validity of this much discussed proposition.

In Fig. 3 heating curves are given to show the effect of maintaining a steel for different lengths of time at the tempering temperature. The 0.95 per cent $\mathrm{C}$ steel, hardened by being quenched in oil from $800^{\circ} \mathrm{C}$, was used. Specimens were maintained for 5 , 30 , and 60 minutes at each of the two tempering temperatures, 200 and $230^{\circ} \mathrm{C}$, chosen because they represent temperatures at which tempering is well in progress, but not to such an extent as to eliminate the thermal effect.

It may be noted from these curves and the compiled data of Table 2: (I) That the beginning of $A c_{t}$ is higher for a long than for a short exposure at the tempering temperature; (2) that the intensity of the transformation is less for a long tempering period than for a shorter one; and (3) that the rate of progress of the transformation is greater at the higher tempering temperature than at the lower one.

From (I) and (2) it is apparent that time has a decided effect on the transformation characteristics. The third conclusion is evident from the fact that at $200^{\circ} \mathrm{C}$ an exposure of 60 minutes is necessary to reduce markedly the intensity of $\mathrm{Ac}_{\mathrm{t}}$, while at a temperature only $30^{\circ} \mathrm{C}$ higher the intensity is much more strongly reduced by a $30-$ minute exposure. This is in agreement with the tempering experiments of Barus and Strouhal, ${ }^{11}$ whose measurements of electrical resistance and thermal emf show the rate of transformation to be much greater at the higher tempering temperatures in the $\mathrm{Ac}_{\mathrm{t}}$ range. This indicates further that the tempering time of 30 minutes used in the preceding section represents actual equilibrium or zero-rate conditions at the temperature of the end of $\mathrm{Ac}_{t}$, though, of course, not at lower temperatures. 
TABLE 2.-Thermal Characteristics of Hardened Carbon Steels

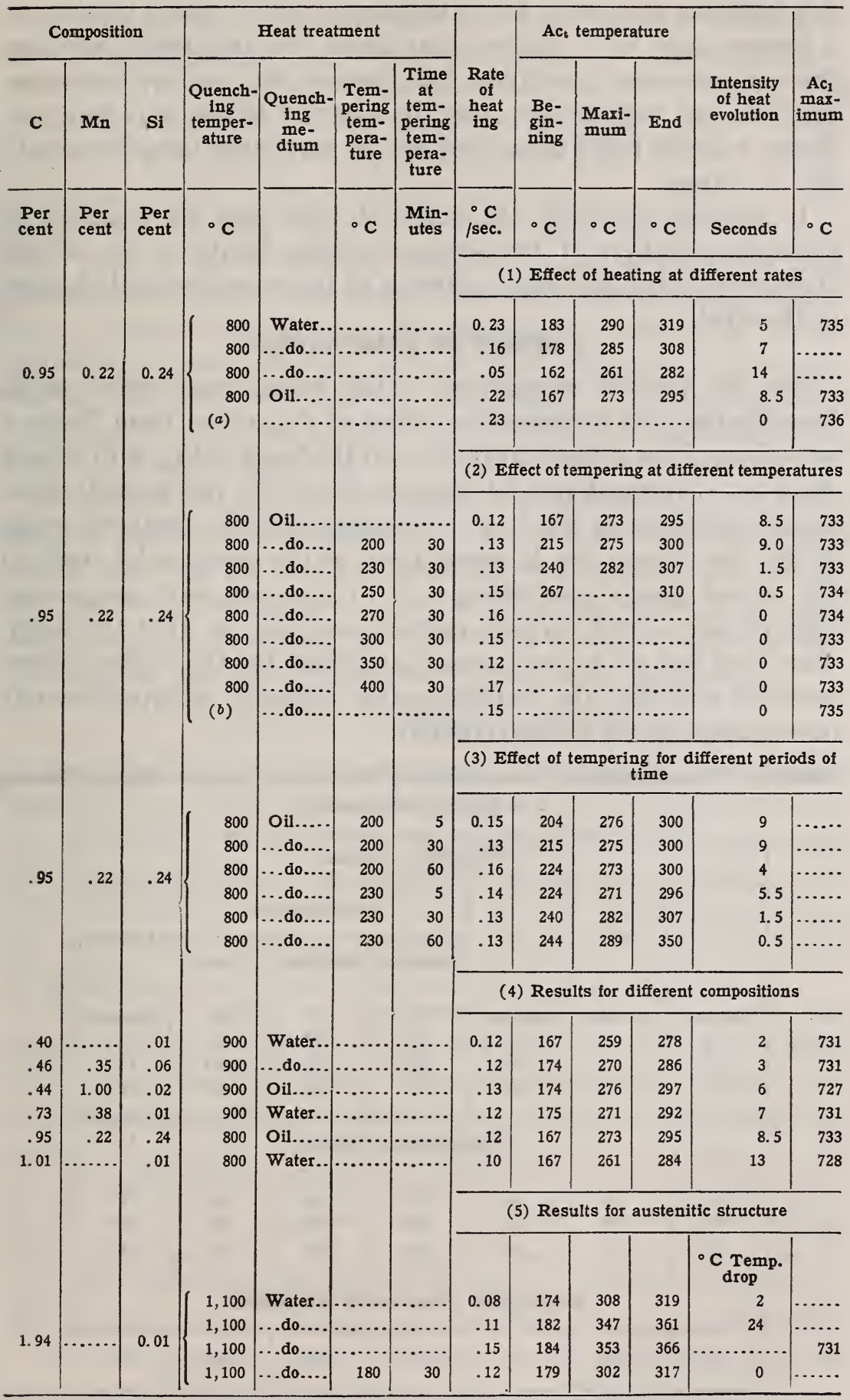

a Annealed.

$b$ Air cooled. 
It may be inferred from the nearly identical characteristics of $\mathrm{Ac}_{\mathrm{t}}$ following tempering for 60 minutes at $200^{\circ} \mathrm{C}$ and 5 minutes at a temperature $30^{\circ} \mathrm{C}$ higher, that these two treatments produce the same structural condition, but, because the rate of transformation changes with temperature, it does not follow that this particular relation holds quantitatively for any other temperatures in the $\mathrm{Ac}_{\mathrm{t}}$ range.

In general, however, the effect of time may be regarded as equivalent to that of temperature within limits as far as the characteristics of $A c_{t}$ are a criterion of the constitutional changes in the steel.

\section{EFFECT OF COMPOSITION}

For the sake of comparison of the several martensitic steels investigated, the temperature values of $\mathrm{Ac}_{t}$ taken from Table 2 have been given a small correction on the basis of Fig. 6 to reduce them to a constant rate of heating of $0.10^{\circ} \mathrm{C}$ per second; these values are given in Table 3 . By comparing the synthetic steels in the first group, low in manganese, or the commercial steels in the second group, containing 0.20 to 0.40 per cent manganese, with respect to the variable carbon, one may see that the maximum and end of $A c_{t}$ are somewhat higher for the higher carbon contents and that the transformation intensity is approximately proportional to the carbon content.

TABLE 3.-Transformation Characteristics of Martensitic Steels for Rate of Heating of $0.10^{\circ} \mathrm{C}$ per Second

\begin{tabular}{|c|c|c|c|c|c|c|}
\hline \multicolumn{7}{|c|}{ SYNTHETIC STEELS } \\
\hline \multirow{2}{*}{ C } & \multirow{2}{*}{ Mn } & \multirow{2}{*}{ Si } & \multicolumn{3}{|c|}{$A c_{s}$ temperature } & \multirow{2}{*}{ Intensity } \\
\hline & & & Beginning & Maximum & End & \\
\hline Per cent & Per cent & Per cent & ${ }^{\circ} \mathrm{C}$ & ${ }^{\circ} \mathrm{C}$ & ${ }^{\circ} \mathrm{C}$ & Seconds \\
\hline 0.40 & $\ldots \ldots \ldots$ & 0.01 & 165 & 255 & 274 & 2 \\
\hline 1.01 & .......... & .01 & 167 & 261 & 284 & 13 \\
\hline$a 1.94$ & .... & .01 & 177 & 298 & 313 & 32 \\
\hline \multicolumn{6}{|c|}{ COMMERCIAL STEELS } & - \\
\hline .46 & .35 & .06 & 172 & 266 & 282 & 3 \\
\hline .73 & .38 & .01 & 173 & 267 & 288 & 7 \\
\hline .95 & .22 & .24 & 165 & 269 & 291 & 8.5 \\
\hline \multicolumn{7}{|c|}{ SYNTHETIC 1 PER CENT MN STEEL } \\
\hline .44 & 1.00 & .02 & 170 & 270 & 291 & 6 \\
\hline
\end{tabular}

a Martensitic by immersion in liquid air; curve 4, Fig. 5 . 
The effect of an increase of carbon on the heat evolution is to augment correspondingly the rate at a given stage in the progress of the transformation for a given furnace rate. This increase in rate from the effect noted in Section III-r, on rate of heating, will raise the temperature of the maximum and end of $A c_{t}$. The increase in temperature of the maximum and end of $A c_{t}$ with increasing carbon, being small, is probably due entirely to the augmented rate of heating. This factor being ineffective for very slow or zero rate of heating, it may be stated that, for this case, the carbon does not inaterially affect the maximum and end of $\mathrm{Ac}_{\mathrm{t}}$. Likewise, the rate at the beginning is unaffected by the subsequent heat evolution, so that the constancy of that point verifies the conclusion that the temperature of $A c_{t}$ is practically independent of carbon content under conditions which render the effect of intensity impotent.

From Table 3 it may be of interest to note further that $A c_{t}$ is slightly higher in the commercial than in the pure synthetic steels of the same carbon content, and that the characteristics of $\mathrm{Ac}_{\mathrm{t}}$ for the steel containing 0.73 per cent carbon and 0.38 per cent manganese are practically identical with those for the steel containing 0.44 per cent carbon and r.o per cent manganese.

\section{EFFECT OF AUSTENITIC STRUCTURE}

For obtaining the data presented in preceding sections, the material used was a martensitic steel, but it was believed to be of some interest to study also the thermal changes accompanying the decomposition of an austenitic matrix in a carbon steel. With this in mind, a steel of $\mathrm{r} .94$ per cent $C$ content was quenched in water, the resulting structure being uniformly austenitic (Fig. $7 a$ ).

The curves taken on specimens given such treatment are shown in Fig. 5, curves $I, 2$, and 3 , and the data taken from them, are shown in Table 2. The transformation observed was very intense, and in one case (Fig. 5, curve 3) the heating advanced so rapidly that the operator could not follow it. In every case the heat evolution increased the specimen temperature at the end of the transformation so that it exceeded the normal furnace temperature, and a drop of temperature was then recorded. This amounted to $2^{\circ} \mathrm{C}$ in curve $I$ and $24^{\circ} \mathrm{C}$ in curve 2 ; the drop for curve 3 , though not recorded, was very considerable.

In these austenitic steels the effect of rate of heating upon the temperature of $A c_{t}$ is much more pronounced than in the marten- 
sitic steels, though with slow rates the difference between the two types of steel is small, if any. Thus by comparison of curve $I$ for the austenitic steel (rate of heating, $0.08^{\circ} \mathrm{C}$ per second) with the curve for the 0.95 per cent $\mathrm{C}$ steel (rate of heating, $0.16^{\circ} \mathrm{C}$ per second), in both of which cases the rate is approximately the same at the maximum, one may note that the maxmum for the austenitic steel is $23^{\circ} \mathrm{C}$ higher and the end only $\mathrm{II}^{\circ} \mathrm{C}$ higher than for the martensitic steel, even though an actual temperature drop occurred in the former case. This would indicate that for very slow rates there would be little temperature difference between $A c_{t}$ for a martensitic structure and $A c_{t}$ for an austenitic one. Here again the fact that the beginning for both is practically the same verifies the conclusion that the heat evolution of the transformation materially affects its observed temperature for sensible rates of heating.

Curve 4 of Fig. 5 shows the thermal characteristics of one of the austenitic steels after exposure for 30 minutes in liquid air. This treatment rendered the steel partially martensitic in structure (Fig. $7 b$ ). Comparison of the heating curve 4 for this sample with curve 2 , the rate of heating being essentially the same in both cases, shows that treatment in liquid air causes (I) a lowering of the maximum and end of the transformation by about $45^{\circ} \mathrm{C}$, and (2) an evolution of heat much less intense, without any recorded drop of temperature. This indicates a marked structural change, evidently from austenite to martensite, on immersion of the austenitic steel in liquid air.

Further examination of the heating curves of the austenitic steels reveals another significant phenomenon. An inflection in these curves may be noted at $273^{\circ} \mathrm{C}$ for curve $2,285^{\circ} \mathrm{C}$ for curve 3 , and somewhat lower for curve $I$, at which temperature there is an augmentation of the rate of heating. It is evident from curves 2 and 4 that the heat evolution of the latter (martensitic) steel starts to drop off, while the former (austenitic) steel is considerably intensified just above the inflection temperature of $273^{\circ} \mathrm{C}$. This indicates two stages in the decomposition of the austenitic steel-namely, the low-temperature stage, probably a manifestation of the simple carbide precipitation, and the hightemperature stage, which is the same intensified by the $A_{3}$ and $\mathrm{A}_{2}$ transformation. In the case of the martensitic steel the change designated by $\mathrm{Ac}_{\mathrm{t}}$ is very probably due only to the carbide precipitation. 
Scientific Papers of the Bureau of Standards, Vol. 16

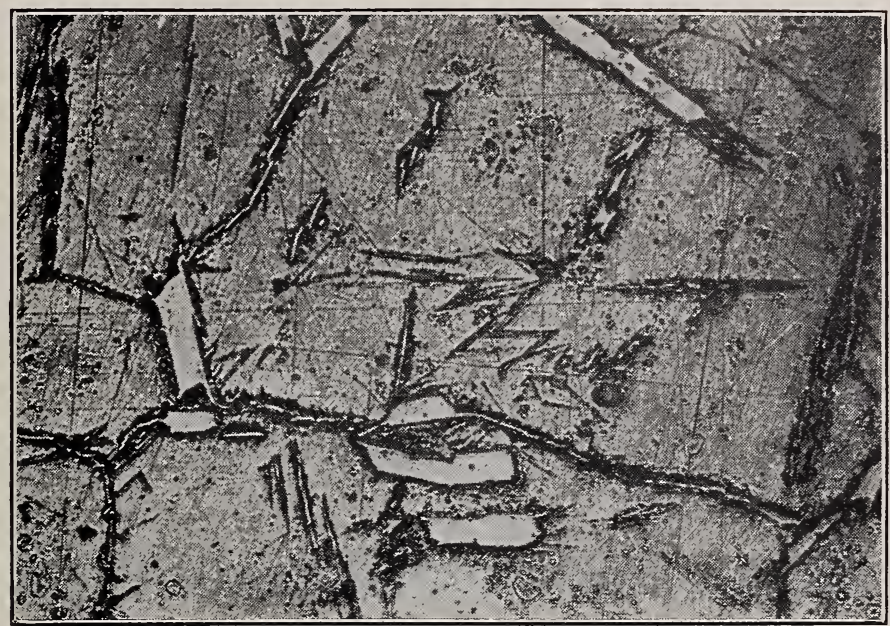

(a)

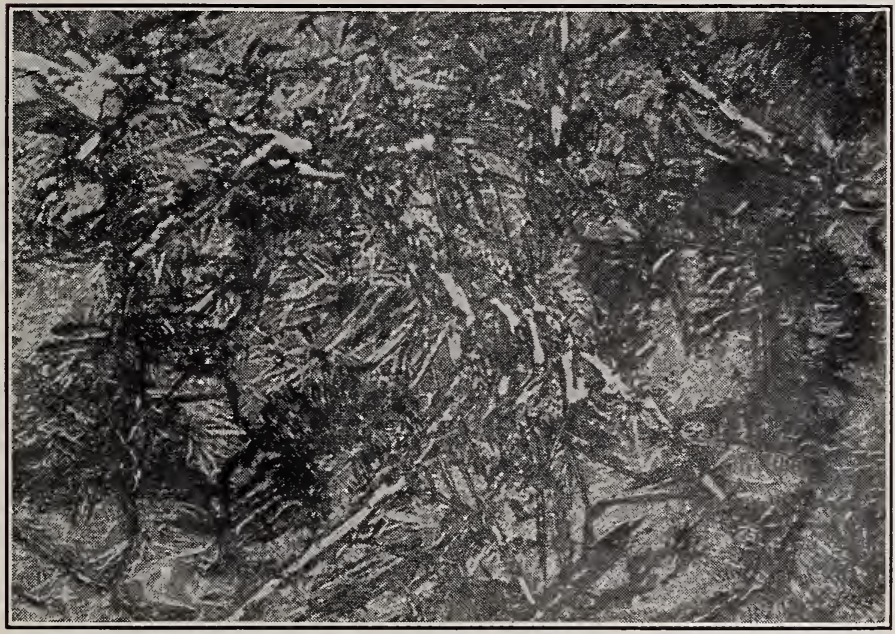

(b)

FIG. 7.-Microstructure of $I .94$ per cent $C$ steel quenched in water from $I I O O^{\circ} \mathrm{C}$. Etched with 2 per cent alcoholic $\mathrm{HNO}_{3}$

(a) As quenched. $\times_{500}$

(b) Same as $(a)$, but dipped in liquid air for 30 minutes. $\times_{200}$ 


\section{RELATION OF CHANGES IN PHYSICAL PROPERTIES TO HEAT EVOLUTION}

The thermal curves presented here show a rapidly increasing heat evolution $\left(\mathrm{Ac}_{\mathrm{t}}\right)$ from $\mathrm{I} 55^{\circ} \mathrm{C}$ to $250^{\circ} \mathrm{C}$ (ending abruptly at about $260^{\circ} \mathrm{C}$ ) for a very slow heating rate. This last temperature, $260^{\circ} \mathrm{C}$, very probably represents the completion of the change from martensite into troostite. A consideration of the changes in physical properties on tempering quenched steels through the $A c_{t}$ range should, therefore, assist materially in determining other characteristics of this change.

\section{MARTENSITIC STEEL}

In order to make a reliable comparison of the characteristics of $\mathrm{Ac}_{\mathrm{t}}$ with the changes in the standard scleroscope and Brinell hardness numbers, measurements were made on samples of the 0.95 per cent $\mathrm{C}$ steel used for the majority of the thermal curves. The results are shown in Figs. 8 and 9, the recording scleroscope being used in the first case and the usual Brinell equipment in the latter. A fresh surface of the ball was taken for every impression. ${ }^{12}$

For the purpose of comparing some of the other physical properties with the heat evolution, Fig. Io was prepared. Curves I and 2 of this figure were obtained from the magnetic data of Burrows and Fahy ${ }^{13}$ and are expressed in gausses per square centimeter; curves 3 and 4 were obtained from the electric resistance and thermal emf data of Campbell, ${ }^{14}$ and curve 5 was obtained from the density values of Schulz. ${ }^{15}$ In all cases martensitic carbon steels were used of approximately the same carbon content as the 0.95 per cent $\mathrm{C}$ steel used here.

Upon returning to the hardness curves of Figs. 8 and 9 one may see that the scleroscope hardness does not drop off abruptly until slightly above the temperature $\left(260^{\circ} \mathrm{C}\right)$ of the end of $A c_{t}$, and that the Brinell hardness begins to drop linearly immediately above the beginning of $\mathrm{Ac}_{\mathrm{t}}$. Thus there exists in both the hardness curves an inflection closely related to fundamental temperature characteristics of the heat evolution.

Consideration next of curves I and 2, Fig. Io, for coercive force and maximum induction, respectively, will show that these

12 Since these Brinell data were obtained, the work of Chevenard (see footnote 5) appeared, containing a curve for an 0.85 per cent $C$ steel practically identical in form with Fig. 9, with the exception that his values are somewhat lower.

13 Burrows and Fahy, Trans. A. S. T. M., 19, part II, p. 5; Igrg.

14 Campbell, J. Iron and Steel Inst., 94, p. 268; I9I6.

15 Schulz, Forschungsarbeiten, No. 16r, p. 1 ; 1914. 
properties change with an increasing rate over the range 20 to $300^{\circ} \mathrm{C}$ in the same manner as the heat evolution. The tempering temperature steps were not taken sufficiently close to define the end point of this change, but it coincides substantially with the end of $A c_{t}$. The curves 3 and 4 , for thermal emf against pure iron and specific resistance, respectively, are practically parallel and may, therefore, be considered as a unit. It may be observed

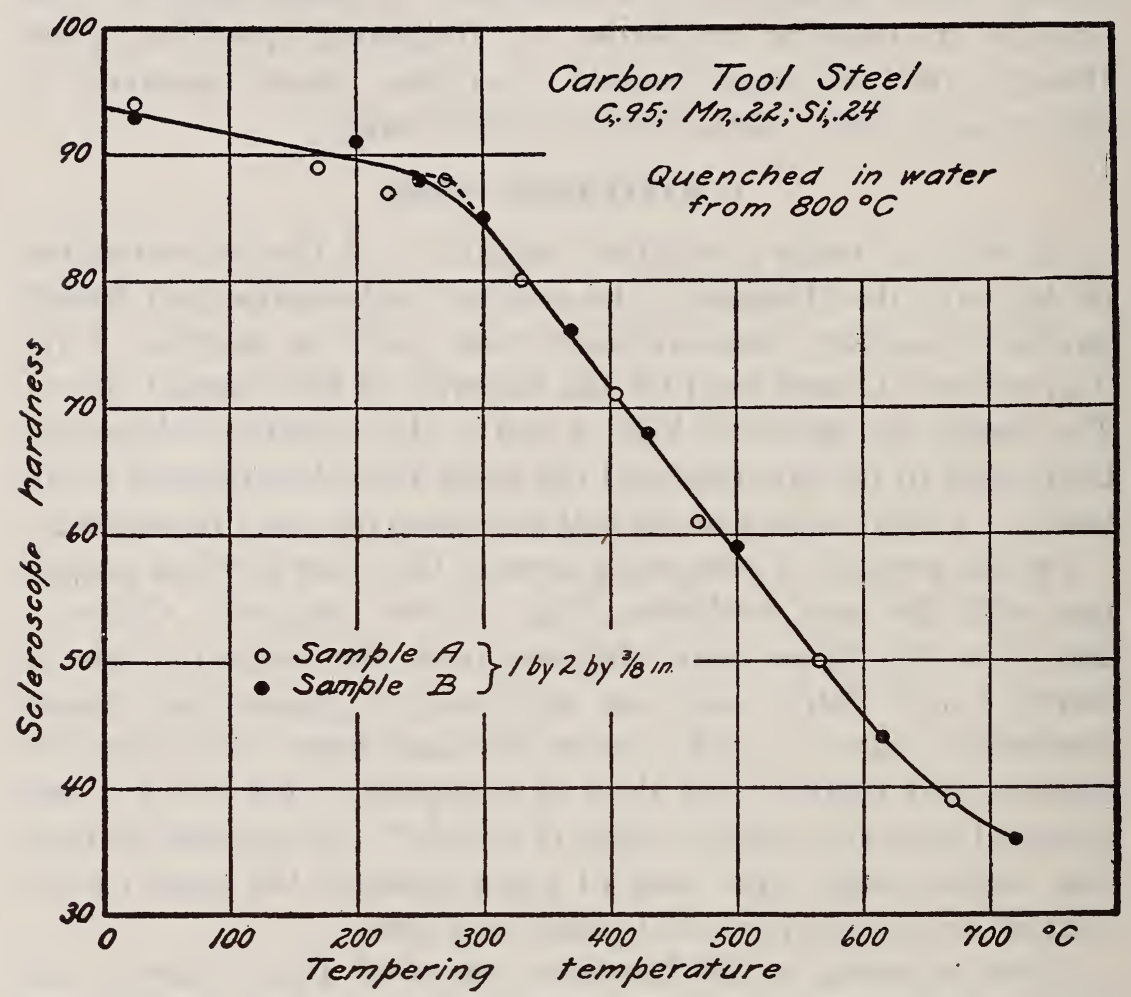

Fig. 8.-Effect of tempering temperature on scleroscope hardness of 0.95 per cent $C$ steel

that the change is about 85 per cent complete at $300^{\circ} \mathrm{C}$, or in the $\mathrm{Ac}_{\mathrm{t}}$ range. The density curve 5 is somewhat irregular, but the maximum rate of change occurs in the vicinity of the end of $\mathrm{Ac}_{i}$.

From the foregoing analysis it is evident that the changes in the physical properties considered are related very closely to the heat evolution $\mathrm{Ac}_{t}$, particularly in the case of the magnetic properties, maximum induction, and coercive force. These relations are forceful indications of a natural boundary between martensite and the troostite produced at about $260^{\circ} \mathrm{C}$ on tempering. Such a boundary should be detectable also by the changes in micro- 
structure. Authorities, however, differ on the temperature of this boundary for simple steels, and place it anywhere in the range from $250^{\circ} \mathrm{C}$ to $400^{\circ} \mathrm{C}$. Careful observers have studied this change, and while not suggesting an end point, have made observations indicative of one in the region of the end of $\mathrm{Ac}_{\mathrm{t}}$.

Howe and Levy, ${ }^{16}$ after quenching eutectoid carbon steel from i $100^{\circ} \mathrm{C}$ to water, find that on a 5 -minute exposure to $300^{\circ} \mathrm{C}$

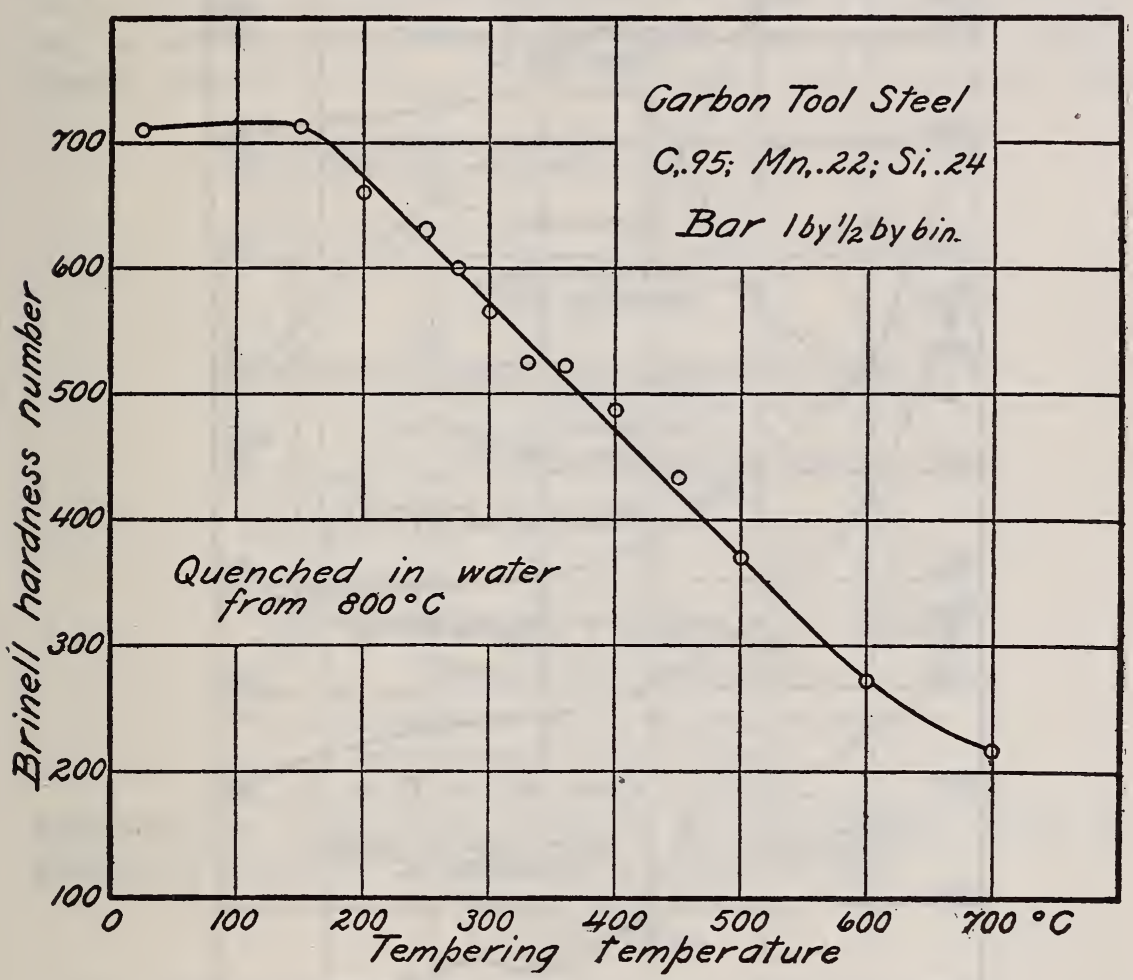

FIG. 9.-Effect of tempering temperature on Brinell hardness of 0.95 per cent $C$ steel

the original white martensite needles are almost completely broken up. Heyn ${ }^{17}$ notes a coarsening of the needle structure at $275^{\circ} \mathrm{C}$.

These observations are indicative of a structural change in the vicinity of the end of the heat evolution. The region under investigation is thus narrowed down, and future observers should have little difficulty in defining precisely the nature of the accompanying changes.

16 Howe and Levy, Trans. A. S. T. M., 16, part II, p. 7; 1916.

${ }^{17}$ Heyn quoted by Sauveur, The Metallography and Heat Treatment of Steel, p. 304. 


\section{AUSTENITIC STEEL}

In a foregoing section (p. 550) attention was called to a sharp change in direction of the heating curves of the austenitic steel. This inflection, denoting an abrupt increase in the rate of heat evolution, was noted to start at about the temperature at which

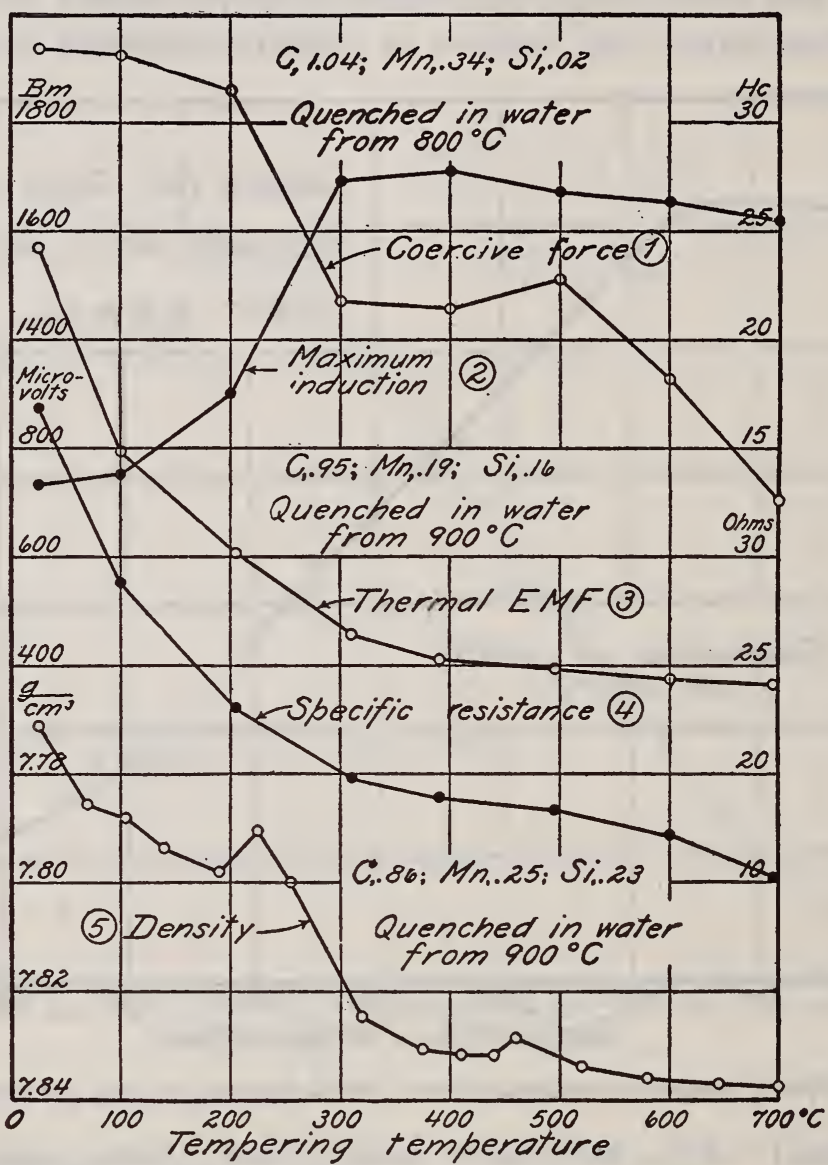

FIG. Io.-Change of physical properties with tempering temperature of martensitic carbon steels

the heat evolution in a martensitic steel begins to disappear. It may therefore be of some interest to compare this thermal behavior of the steel with the density changes in similar steel.

In Fig. I I are plotted density values given by Maurer ${ }^{18}$ for a I.66 per cent $\mathrm{C}$ steel quenched in water from $\mathrm{I}, 050^{\circ} \mathrm{C}$. The resulting structure is not completely austenitic, but nearly so. 
The curve shows three distinct regions: (I) 20 to $150^{\circ} \mathrm{C}$, in which the density increases as in a martensitic steel; (2) I 50 to $250^{\circ} \mathrm{C}$, in which a drop occurs which recalls the second stage of the heat change of the austenitic steel; and (3) above $250^{\circ} \mathrm{C}$, in which it follows the normal course of a martensitic steel. Since martensitization implies a decrease in density (see the black circles of Fig. I I, representing the density change on immersion in liquid air), the second step with a density drop is evidently attributable to completion of the change from austenite to martensite, which is more or less transformed into troostite. The

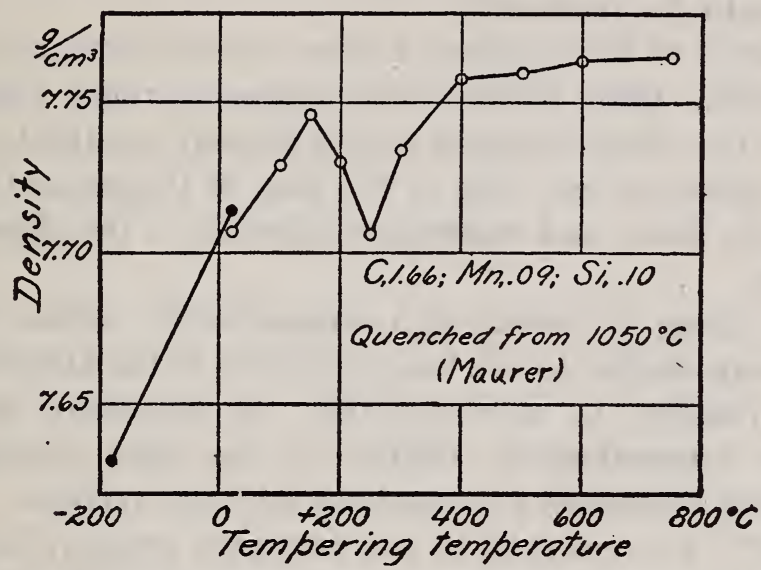

FIG. II.-Change in density with tempering temperature of semiaustenitic carbon steel (Maurer)

augmentation of the heat evolution of the austenitic steels, as previously explained, is therefore definitely verified.

\section{SUMMARY}

The transformation, observed as an evolution of heat, on heating curves of hardened steel has been designated here as $A c_{t}$, and its characteristics as revealed in carbon steels have been investigated. The effect of several variables was noted with the following conclusions:

I. An increase in the rate of heating raises markedly the temperature of $A c_{t}$ for a 0.95 per cent $\mathrm{C}$ martensitic steel and has a yet more marked effect for an austenitic carbon steel. For zero rate of heating there appears, however, to be little, if any, difference between the principal temperatures, whether the steel is of high or low carbon content or whether it is martensitic or austenitic. The principal temperatures for the 0.95 per cent $\mathrm{C}$ martensitic 
steel were found to be $\mathrm{I} 55,250$, and $260^{\circ} \mathrm{C}$, respectively, for the beginning, maximum, and end.

2. The results obtained for specimens tempered at different temperatures before taking heating curves confirm substantially the temperature of the end of $\mathrm{Ac}_{\mathrm{t}}$ just given.

3. Tempering for a short time at a temperature within the $A c_{t}$ range has an effect on the transformation characteristics similar to tempering for a longer time at a somewhat lower temperature.

4. The heat evolution of the austenitic steel takes place in two steps, the second being probably connected with the transition from austenite to martensite.

5. A survey of the changes in some physical properties of martensitic carbon steels through the tempering range leads to the conclusion that these changes are all directly related to the heat evolution observed, but only in the case of the magnetic properties, coercive force, and maximum induction is the change of the same type.

6. The change in density of a semiaustenitic carbon steel proceeds in steps similar to the heat evolution of the austenitic steel.

7. The changes in microstructure on tempering martensitic steels are unquestionably related to the heat evolution, but further study is necessary to establish fully this relation. The end point $\left(260^{\circ} \mathrm{C}\right.$ for zero rate) of $A c_{t}$ may very properly be taken as the natural boundary between martensite and the troostite of tempering, representing as it does the end of the transformation suppressed on rapid cooling.

The competent assistance of $\mathrm{H}$. A. Wadsworth has greatly facilitated this investigation.

Washington, April 22, 1920. 